\title{
Hypercholesterolemia impairs oxytocin-induced uterine contractility in late pregnant mouse
}

\author{
Amol R Padol ${ }^{1}$, Susanth V Sukumaran ${ }^{1}$, Abdul Sadam¹, Manickam Kesavan ${ }^{1}$, \\ Kandasamy Arunvikram¹, Ankita D Verma², Vivek Srivastava1, Manjit Panigrahi², \\ Thakur Uttam Singh ${ }^{1}$, Avinash G Telang ${ }^{1}$, Santosh K Mishra ${ }^{1}$ and Subhashree Parida ${ }^{1}$ \\ ${ }^{1}$ Division of Pharmacology and Toxicology, ICAR-Indian Veterinary Research Institute, Izatnagar, Bareilly, \\ Uttar Pradesh, India and ${ }^{2}$ Division of Animal Genetics and Breeding, ICAR-Indian Veterinary Research Institute, \\ Izatnagar, Bareilly, Uttar Pradesh, India
}

Correspondence should be addressed to S Parida; Email: subhaparida1210@gmail.com

\begin{abstract}
High cholesterol is known to negatively affect uterine contractility in ex vivo conditions. The aim of the present study was to reveal the effect of in vivo hypercholesterolemia on spontaneous and oxytocin-induced uterine contractility in late pregnant mouse uterus. Female Swiss albino mice were fed with high cholesterol (HC) diet (0.5\% sodium cholate, $1.25 \%$ cholesterol and $15 \%$ fat) for 6 weeks and then throughout the gestation period after mating. On day 19 of gestation, serum cholesterol level was increased more than 3-fold while triglycerides level was reduced in HC diet-fed animals as compared to control animals fed with a standard diet. In tension experiments, neither the mean integral tension of spontaneous contractility nor the response to $\mathrm{CaCl}_{2}$ in high $\mathrm{K}^{+}$-depolarized tissues was altered, but the oxytocin-induced concentration-dependent contractile response in uterine strips was attenuated in hypercholesterolemic mice as compared to control. Similarly, hypercholesterolemia dampened concentration-dependent uterine contractions elicited by a GNAQ protein activator, Pasteurella multocida toxin. However, it had no effect on endogenous oxytocin level either in plasma or in uterine tissue. It also did not affect the prostaglandin release in oxytocin-stimulated tissues. Western blot data showed a significant increase in caveolin-1 and GRK6 proteins but decline in oxytocin receptor, GNAQ and RHOA protein expressions in hypercholesterolemic mouse uterus. The results of the present study suggest that hypercholesterolemia may attenuate the uterotonic action of oxytocin in late pregnancy by causing downregulation of oxytocin receptors and suppressing the signaling efficacy through GNAQ and RHOA proteins.

Reproduction (2017) 153 565-576
\end{abstract}

\section{Introduction}

Cholesterol plays a vital role in the modulation of membrane fluidity and forms the major component of membrane microdomains, such as lipid rafts and caveolae. These domains of the plasma membrane are important loci for signaling pathways. Many GPCRs along with their immediate downstream signaling molecules are known to be located in caveolae (Villar et al. 2016). Compartmentalization of these molecules plays an important role in cell signaling involved in the regulation of uterine contractility (Brainard et al. 2005, Draeger et al. 2005). Besides, cholesterol acts as the precursor of most of the steroid hormones namely; estrogen, progesterone and cortisol which have a major role in the maintenance of pregnancy and induction of labor at term.

Cholesterol is critically involved in membrane receptor activity and stability. Thermal stability of rhodopsin is enhanced by an increase in cholesterol which is supposed to be the result of the indirect action of the later on membrane fluidity (Soubias \& Gawrisch 2013). In contrast, $\beta_{2}$-adrenoceptor displays three to five high-affinity binding sites for direct interaction with cholesterol (Gater et al. 2014). Older studies report that high-affinity oxytocin receptors (OXTR) remain enriched in cholesterol-loaded part of the cell membrane (Gimpl \& Fahrenholz 2000) and stay protected from thermal and $\mathrm{pH}$ denaturation (Gimpl \& Fahrenholz 2002). Cholesterol also induces a compact conformational state (Muth et al. 2011), affects the binding affinity (Gimpl et al. 1997) and downstream signaling of OTRs (Reversi et al. 2006). Like $\beta_{2}$-adrenoceptor, OTR is supposed to have sensitive binding sites for direct interaction with cholesterol (Wiegand \& Gimpl 2012).

$A$ rise in both circulating and uterine tissue cholesterol level has been reported during pregnancy (Potter \& Nestel 1978). The abnormal rise of cholesterol in uterine tissue strips has been shown to reduce spontaneous as well as oxytocin-induced uterine activity (Smith et al. 2005). The same study also demonstrated the reversal and accentuation 
of uterine activity by cholesterol depletion with methyl- $\beta$ cyclodextrin. Appropriate induction of uterine contraction is mediated by a protective liver $X$ receptor $\beta$ mechanism which prevents the accumulation of cholesterol in the uterus (Mouzat et al. 2007). Increased plasma cholesterol is positively correlated with obesity (Gostynski et al. 2004). Clinically, obese women are reported to be at increased risk of undergoing induction of labor and emergency Caesarean section (Weiss et al. 2004). Accordingly, Elmes and coworkers (Elmes et al. 2011) reported adverse lipid profiles and decreased the expression of key markers of uterine contractility during parturition due to feeding a high-fat, high cholesterol diet in a rat model.

OXTR expression in the myometrium increases about 12 -fold from early pregnancy to term, and a further increase occurs during labor (Arthur et al. 2008). The upregulation of myometrial OXTR expression results in an enhanced sensitivity of the uterus to oxytocin at term, which argues for a vital role of the OXTR/oxytocin system in the mechanism of labor onset and maintenance. OXTR is coupled to the GNAQ, a class of guanosine triphosphate (GTP) binding proteins. The GNAQ/phospholipase C (PLC)/inositol 1,4,5-triphosphate (InsP3) pathway is the major pathway mediating the signal of OXTR. Binding of OT to OXTR during labor activates GNAQ; and IP3 thus generated ultimately releases $\mathrm{Ca}^{2+}$ from the sarcoplasmic reticulum (Noble et al. 2006). GNAS also causes activation of voltage-regulated $\mathrm{Ca}^{2+}$ channels (Sanborn et al. 2005) and $\mathrm{Ca}^{2+}$ entry into the cells. $\mathrm{Ca}^{2+}$ binds to calmodulin, and the $\mathrm{Ca}^{2+}$-calmodulin complex activates MLC kinase, resulting in myometrial contraction.

Cholesterol depletion by methyl- $\beta$-cyclodextrin in guinea pig myometrium enhanced both spontaneous and agonist-evoked contractility in a reversible manner (Buxton \& Vittori 2005). Zhang and co-authors (Zhang et al. 2007) reported the deleterious effect of elevated cholesterol on contractility and $\mathrm{Ca}^{2+}$ signaling in human myometrium. However, these studies did not explore the effect of hypercholesterolemia on uterine activity. In a recent study, Muir and coworkers (Muir et al. 2016) described the adverse effects of high cholesterol diet producing obesity on uterine contractility of rats in labor. This group demonstrated that high-fat diet attenuated oxytocin-induced contraction at term. However, paradoxically, they observed an increase in the density of oxytocin receptor expression in uterine tissues from high fat-fed animals. Thus, the mechanisms of reduced uterine contractions under the influence of high cholesterol level remain to be clarified. In the current study, we used a mouse model to examine the effect of hypercholesterolemia on spontaneous and oxytocin-induced uterine contractility and mechanisms involved leading to such an effect. We preferred a mouse model as mice are $99 \%$ homologous to the human genome (Mouse Genome Sequencing Consortium et al. 2002) and knock-out mice models can be used for the confirmation of the involved pathways in future.

\section{Materials and methods}

\section{Animals and diet}

All animal procedures employed in the study were approved by the Institutional Animal Ethics Committee and all mice and fetuses were humanely killed. Twenty recently weaned virgin Swiss albino female mice weighing 12-16g were procured from the Laboratory Animal Resource Section of the Institute and group housed (five per cage) under standard laboratory conditions outlined in Committee for the Purpose of Control and Supervision of Experiments on Animals (CPCSEA) guidelines. After an acclimatization period of seven days, mice were randomly assigned to control and high cholesterol groups and fed standard rodent diet and high cholesterol diet respectively. High cholesterol diet was formulated by mixing $0.5 \%$ sodium cholate, $1.25 \%$ cholesterol and $15 \%$ fat to standard rodent diet (Shi et al. 2002). High cholesterol diet had a calorific content of $5.19 \mathrm{kcal} / \mathrm{g}$, which was higher than the control diet $(4.49 \mathrm{kcal} / \mathrm{g})$. High cholesterol diet was prepared fresh daily and the feed remaining from the previous day feeding was removed from the cage before providing fresh feed to the animals.

\section{Mating and labor induction}

Mice from both the groups were fed their respective diets for the pre-mating period of 6 weeks. On day 42 mice were mated with the same age group males in the ratio of $1: 1$. All the animals underwent successful mating within 3-4 days of cohabitation. Mating was confirmed by the appearance of the vaginal plug in the vaginal opening of mice. The day of appearance of the vaginal plug was recorded and considered as gestation day 0.5 . Following mating, pregnant females were separated from males and maintained on their respective diet until parturition. For oxytocin-induced labor, the animals were injected with oxytocin subcutaneously at $3 \mathrm{U} /$ day in four divided doses from the gestation day 17.5. The injections were continued every $6 \mathrm{~h}$ up to parturition. This protocol was followed, based on a recent study (Grotegut et al. 2016) with certain modification. Weekly body weight was recorded during pre-mating and gestation period.

\section{Sample collection}

Another set of animals were killed by cervical dislocation on day 19 of pregnancy. Blood samples were collected through orbital plexus puncture to the heparinized tubes and plasma was separated. Plasma samples were aliquoted and stored at $-20^{\circ} \mathrm{C}$ for further analysis. Uterus was dissected and transferred to ice-cold modified Krebs-Henseleit solution (MKHS) with following composition (in $\mathrm{mM}$ ): $\mathrm{NaCl} 118, \mathrm{KCl} 4.7, \mathrm{CaCl}_{2}$ 2.5, $\mathrm{MgSO}_{4}$ 1.2, $\mathrm{NaHCO}_{3} 11.9, \mathrm{KH}_{2} \mathrm{PO}_{4} 1.2$ and D-glucose $11.1(\mathrm{pH} 7.4)$. Fetuses were removed and separated from their fetal membranes and placentas and weighed. Fetuses were then killed by injection of $0.1 \mathrm{~mL}$ thiopental sodium solution $(200 \mathrm{mg} / \mathrm{mL})$ into the fat pad located between the scapulas. Uterine samples were also stored in RNAlater solution (Qiagen) for real-time PCR and snap frozen for Western blot at $-80^{\circ} \mathrm{C}$. Renal and intra-scapular adipose tissue depots from both groups of dams were carefully dissected and weighed. 


\section{Lipid profile}

Total cholesterol and triglycerides in the plasma and uterine tissue were estimated through commercially available kits (Span Diagnostics Ltd., Surat, India) following manufacturer's instructions. Standards were used as supplied in the kit and the contents of cholesterol and triglycerides in the samples were obtained from a formula using the ODs of standard and of test. Plasma cholesterol and triglycerides were assayed by adding $1 \mathrm{~mL}$ of assay reagent to $10 \mu \mathrm{L}$ sample or standard in duplicate and incubated for $10 \mathrm{~min}$ at $37^{\circ} \mathrm{C}$. The absorbance was then read at $505 \mathrm{~nm}$. Plasma cholesterol and triglycerides contents were expressed as $\mathrm{mg} / \mathrm{dL}$. The duplicates were averaged for each sample before analyzing statistically.

Uterine tissue cholesterol and triglycerides contents were estimated according to the methodologies previously described by Hara and Radin (1978), with some modifications. Uterine tissue samples were subjected to lipid extraction with isopropanol/hexane (2:3 v/v) mixture. Tissue samples (100 mg) were homogenized in $500 \mu \mathrm{L}$ mixture of isopropanol/hexane $(2: 3, v / v)$ with subsequent centrifugation at $2000 \mathrm{~g}$ at $25^{\circ} \mathrm{C}$ for $5 \mathrm{~min}$. After centrifugation, the upper liquid phase was separated and evaporated at $37^{\circ} \mathrm{C}$ under nitrogen and the residual lipid film was resuspended in $1 \mathrm{~mL}$ of ethyl acetate and analyzed using the same procedure as above for plasma and expressed in $\mathrm{mg} / \mathrm{g}$ tissue.

\section{Isometric tension experiments}

Longitudinal uterine strips $(6-8 \mathrm{~mm} \times 2-3 \mathrm{~mm})$ from the midhorn region were mounted between two loops made from 37 gage stainless steel wire in a thermostatically controlled isolated $10 \mathrm{~mL}$ organ bath (Ugo Basile, COMERIO-Varese, Italy) containing MKHS which was continuously bubbled with medical gas $\left(21 \% \mathrm{O}_{2}+5 \% \mathrm{CO}_{2}+74 \% \mathrm{~N}_{2}\right)$ maintained at $37 \pm 1^{\circ} \mathrm{C}$ under a constant passive tension of $0.7 \mathrm{~g}$ throughout the experiment. The uterine strips were washed every $15 \mathrm{~min}$ and equilibrated until they showed regular spontaneous rhythmic contractile activity. Isometric contractions were recorded by means of a high sensitivity force displacement transducer (Model: MTL 0202/D, Power Lab, Bella Vista, NSW, Australia) connected to a computer using the chart v4.1.2 software program (Power Lab).

\section{Experimental protocols for tension experiments}

\section{Assessment of the effect of hypercholesterolemia on spontaneous uterine contractions at term}

After equilibration of the uterine tissue of mice for $60 \mathrm{~min}$ with MKHS, the normal spontaneous contractions were recorded. The frequency (contractions/min) and amplitude (gram tension) were determined and mean integral tension (MIT) was calculated (Parida et al. 2013) using the following formula:

$$
\operatorname{MIT}(\mathrm{g} \min )=\frac{\text { Integral of selected tracing }}{\text { Selection duration in seconds }} \times 60
$$

\section{Assessment of the effect of hypercholesterolemia on} oxytocin-induced uterine contractions

After recording the basal spontaneous uterine activity in both the groups, response to oxytocin was assessed by its in vitro addition into bath solution. After equilibration of uterine tissue for $1 \mathrm{~h}$ in MKHS, concentration response to oxytocin $\left(10^{-12}\right.$ $\left.10^{-6} \mathrm{M}\right)$ was elicited.

\section{Assessment of the effect of hypercholesterolemia on Pasteurella multocida toxin (PMT)-induced uterine contractions}

In order to examine the effect of high cholesterol and/or interaction of cholesterol with $G$ proteins and on subsequent myometrial activity, concentration-response curve to PMT (receptor-independent activator of Gq (GNAQ)) $\left(10^{-13}-10^{-9} \mathrm{M}\right.$ ) was generated in uterine strips from both groups of animals.

\section{Assessment of the effect of hypercholesterolemia on phospholipase C activator m-3M3FBS-induced uterine contractions}

To examine the effect of high cholesterol diet on phospholipase C, $m$-3M3FBS (10-50 mM), a direct activator of phospholipase $\mathrm{C}$ was cumulatively added to the bath at a 5-min interval. In parallel experiments, tissue was incubated with an equal quantity of vehicle (DMSO) before eliciting the concentrationdependent response to $m-3 \mathrm{M} 3 \mathrm{FBS}$.

\section{Assessment of the effect of hypercholesterolemia on $\mathrm{CaCl}_{2}$-induced uterine contractions in $\mathrm{K}+$-depolarized uterine tissue}

To assess any effect of high cholesterol on the voltage-gated $\mathrm{Ca}^{2+}$ channel, concentration-response curve to $\mathrm{CaCl}_{2}$ was elicited after equilibration of uterine tissue in $\mathrm{Ca}^{2+}$ free $40 \mathrm{mM}$ $\mathrm{KCl}$ for $30 \mathrm{~min}$ in uterine strips of control mice and compared with high cholesterol group uterine tissue. The detailed protocol for this experiment has been described elsewhere (Singh et al. 2015).

\section{Western blot analysis}

To determine whether high cholesterol diet influences the expression of caveolin-1(CAV1), OXTR, GNAQ, RHOA and G-protein coupled receptor kinase 6 (GRK6) proteins, uterine tissues from late pregnant mice were subjected to membrane protein extraction, SDS-PAGE and subsequent Western blotting.

Membrane proteins were extracted according to the operating instructions of Membrane Protein Extraction Kit (Boster Bio, Pleasanton, CA, USA). Total protein concentration of each lysate was determined using the Bradford protein assay kit (GeNei, Bangalore, India) according to the manufacturer's instructions.

A total of $30 \mu \mathrm{g}$ membrane protein was mixed with Laemmli sample buffer (Bio-Rad) and boiled for $5 \mathrm{~min}$. Protein lysates were fractionated on $10 \%$ acrylamide gel for OXTR, GNAQ, GRK6, and $\beta$-actin (ACTB) while CAV1 and 
RHOA proteins were fractionated on $15 \%$ acrylamide gel with Tris-glycine SDS buffer (GenDepot, Barker TX, USA) and transferred to nitrocellulose membrane (Bio-Rad). For the separation of OXTR protein, dithiothreitol $(54 \mathrm{mg} / \mathrm{mL})$ was added to Laemmli sample buffer (Devost \& Zingg 2003). Membranes were blocked with $5 \%$ bovine serum albumin in Tris-buffered saline, 1\% Tween 20 (TBST) and probed with primary antibodies to OXTR (Rabbit monoclonal, 1:1000, Abcam), GNAQ (Rabbit polyclonal, 1:200, Santa Cruz Biotechnology), CAV1 (Rabbit polyclonal to CAV1, 1:5000, Abcam), RHOA (Goat polyclonal antibody, 1:500, Santa Cruz Biotechnology), GRK6 (Rabbit polyclonal, 1:500, Santa Cruz Biotechnology), and ACTB (Rabbit polyclonal, 1:5000, Enzo Life Sciences, Inc., Farmingdale, NY, USA) for $12 \mathrm{~h}$ at $4{ }^{\circ} \mathrm{C}$ with agitation. Horseradish peroxidase (HRP)conjugated secondary antibody (Goat anti-rabbit, ICL Inc., Portland, OR, USA) was used at a working concentration of 1:5000 for all except RHOA. For detection of RHOA, HRPconjugated secondary antibody (Donkey anti-goat, Santa Cruz Biotechnology) was used at a dilution of 1:10,000. Bands were developed with DAB peroxidase substrate (Vector Laboratories, Burlingame, CA, USA), subsequently scanned and quantitated by densitometric analysis using the ImageJ 1.4.3.67 Software, NIH.

\section{Estimation of oxytocin level}

Plasma and uterine oxytocin levels were measured quantitatively using a commercially available ELISA kit (Cusabio Biotech Ltd, Wuhan, Hubei Province, China) according to the manufacturer's instructions.

\section{Estimation of oxytocin-induced prostaglandin level}

Uterine tissue strips from both the group of animals were mounted in a thermostatically controlled (at $37 \pm 1^{\circ} \mathrm{C}$ ) organ bath containing MKHS and exposed to $1 \mu \mathrm{M}$ concentration of oxytocin for $20 \mathrm{~min}$. Organ bath was continuously bubbled with medical gas during the incubation. After incubation with oxytocin, tissues were immediately dismounted, snap frozen in liquid nitrogen and stored at $-80^{\circ} \mathrm{C}$ for further analysis of prostaglandins. For estimation of basal prostaglandin production, another set of tissue strips was mounted and incubated in organ bath for $20 \mathrm{~min}$ without any treatment. The tissue samples were homogenized to obtain a $10 \%$ homogenate; and to normalize the total protein in each sample, protein concentration was assayed in homogenate using the commercial kit (Genei) by Bradford's method. Prostaglandin levels were estimated using commercial mouse specific competitive ELISA kit (Blue Gene, Shanghai, China) utilizing a monoclonal anti-PG antibody, following the manufacturer's protocol.

\section{Relative expression of Oxtr mRNA in the uterus}

We employed real-time PCR technique to examine relative expression of Oxtr mRNA in the uterus of control and $\mathrm{HC}$ diet-fed dams. Total RNA was isolated using the RNeasy Plus Mini Kit (Qiagen) as per the manufacturer's instructions. The purity of the RNA was checked by A260/A280 ratio and A230/ A260 ratio in a nanodrop and quantified as $1 \mathrm{OD}=40 \mu \mathrm{g} / \mathrm{mL}$. cDNA was synthesized using High Capacity RNA-to-cDNA Kit (Applied Biosystems). Real-time PCR was conducted using Fast SYBR Green Master mix (Applied Biosystems). Each sample was run in triplicate in a $25 \mu \mathrm{L}$ reaction consisting $12.5 \mu \mathrm{L}$ SYBR Green master mix, $1 \mu \mathrm{L}$ of $10 \mathrm{pM}$ stock solution of each of the gene-specific forward and reverse primers (Oxtr forward 5'-GTGCAGATGTGGAGCGTCT 3', reverse 5' GTTGAGGCTGGCCAAGAG 3' and Gapdh forward 5' AACTTTGGCATTGTGGAAGG 3', reverse 5' ACACATTGGGGGTAGGAACA $3^{\prime}$ ) and $1 \mu \mathrm{L}$ of cDNA; and the volume was made up to $25 \mu \mathrm{L}$ with RNAse-free water. The real-time PCR reaction started with an initial incubation at $95^{\circ} \mathrm{C}$ for $10 \mathrm{~min}$, followed by 35 cycles of amplification with denaturation at $95^{\circ} \mathrm{C}$ for $35 \mathrm{~s}$, annealing at $57^{\circ} \mathrm{C}$ for $30 \mathrm{~s}$ and extension at $72^{\circ} \mathrm{C}$ for $30 \mathrm{~s}$. The result was expressed as threshold cycle values $\left(C_{T}\right)$. The threshold automatically adjusted by the instrument was used for the generation of $C_{\mathrm{T}}$ values.

\section{Drugs}

Oxytocin and $m$-3m3FBS were purchased from Anaspec, USA and Merck, USA respectively. PMT, cholesterol and sodium cholate were from Sigma-Aldrich, USA. Dimethyl sulfoxide (DMSO) served as a vehicle for $m-3 \mathrm{~m} 3 \mathrm{FBS}$. Stock solutions of oxytocin and PMT were prepared in distilled water, stored at $-20^{\circ} \mathrm{C}$ and dilutions were prepared in MKHS just before use. DMSO at the concentrations used was checked to make sure that it had little effect on the responses of the tissue.

\section{Stastistical analysis}

Contractile responses to oxytocin, PMT, $m-3 m 3 \mathrm{FBS}$ and $\mathrm{CaCl}_{2}$ on uterine tissues were expressed as the percentage of MIT of preceding spontaneous contraction response (set at 100\%). Nonlinear regression analysis (sigmoidal dose-response with a variable slope) was used to determine the $E_{\max }$ (the maximal response) and $\mathrm{EC}_{50}$ (the concentration producing $50 \%$ of the maximal response) of agonists by GraphPad Prism version 4 software. The potency of the oxytocin was expressed as $\mathrm{pD}_{2}$ $\left(-\log \mathrm{EC}_{50}\right)$. Results have been expressed as the mean \pm S.E.M. with $n$ equal to the number of animals. To study the relative change in gene expression, the $2^{- \text {ddCT }}$ method was used as described previously by Livak and Schmittgen (2001). The formula used to calculate the fold change in gene expression was 'fold change $=2^{-\mathrm{ddC}}$, ( where, $\mathrm{dd}_{\mathrm{T}}=\left(C_{\mathrm{T}}\right.$ ' Oxtr $-C_{\mathrm{T}}$ ' Gapdh $)$ $\mathrm{HC}-\left(C_{\mathrm{T} \text {, Oxtr }}-C_{\mathrm{T} \text {, Gapdh }}\right)$ control $)^{\prime}$. Data were expressed as fold change with statistics applied on $\mathrm{d}_{\mathrm{T}}$ values of both the groups. Student's $t$-test was employed for comparison between two groups where the data followed normality and Mann-Whitney test to compare data not following a normal distribution. Twoway ANOVA followed by Bonferroni post hoc test was used for multiple comparisons. 
Table 1 Effect of high cholesterol diet on body weight, litter size, fetus weight, renal and scapular fat depot of late pregnant mice.

\begin{tabular}{lccc}
\hline & Control diet & HC diet & $\boldsymbol{P}$-value \\
\hline Body weight (g) at the end of 6 weeks of feeding & $24.82 \pm 0.7(n=15)$ & $22.52 \pm 1.38(n=15)$ & 0.14 \\
Body weight (g) at the end of gestation & $41.35 \pm 1.29(n=15)$ & $45.06 \pm 1.99(n=15)$ & $7.75 \pm 0.84(n=8)$ \\
Litter size & $8.1 \pm 1.01(n=8)$ & $1.11 \pm 0.09(n=8)$ & 0.73 \\
Fetus weight (g) & $1.27 \pm 0.07(n=8)$ & $169.75 \pm 35.51(n=7)$ & 0.18 \\
Renal fat (mg) & $167.23 \pm 24.91(n=6)$ & $300.16 \pm 42.45(n=7)$ & 0.95 \\
Scapular fat (mg) & $238.02 \pm 29.29(n=6)$ & 0.26 \\
\hline
\end{tabular}

Data were analyzed by unpaired $t$-test.

\section{Results}

Effect of high cholesterol (HC) diet on body weight, length of gestation with and without oxytocin treatment, litter size, pup size, renal and scapular fat of mice

Feeding of $\mathrm{HC}$ diet did not influence the body weight of animals during the 6 weeks of feeding as well as gestation (Table 1). Gestation length was not different $(P>0.05)$ between control and HC-group of animals. Oxytocin administration significantly reduced the gestation length in both the groups but it did not affect the gestation length between the groups (Table 2). Either standard or high cholesterol diet had no significant effect on the litter sizes $(P=0.79)$, pup size $(P=0.18)$, renal $(P=0.95)$ and scapular fat $(P=0.26)$ depots of mice (Table 1$)$.

\section{Effect of HC diet on cholesterol and triglyceride level in plasma and tissue}

At the end of gestation period, the plasma cholesterol level was enhanced $(P<0.0001)$ more than three times as compared to standard diet-fed animals $(272.4 \pm 22.04 \mathrm{mg} / \mathrm{dL}, \quad n=7 \quad$ vs $84.51 \pm 4.95 \mathrm{mg} / \mathrm{dL}$, $n=7)$ whereas the triglyceride level was significantly $(P=0.026)$ reduced $(82.75 \pm 13.95 \mathrm{mg} / \mathrm{dL}, n=7 \quad$ vs $52.22 \pm 4.88 \mathrm{mg} / \mathrm{dL}, n=7$ ) (Fig. 1A). Uterine tissues collected after killing the animals showed significant rise $(P=0.003)$ in cholesterol level $(2.69 \pm 0.3 \mathrm{mg} / \mathrm{g}, n=8$ vs $1.15 \pm 0.33 \mathrm{mg} / \mathrm{g}, n=5$ ) though the triglyceride levels did not vary $(2.14 \pm 0.37 \mathrm{mg} / \mathrm{g}, n=7$ vs $1.8 \pm 0.35 \mathrm{mg} / \mathrm{g}$, $n=5, P=0.54$ ) (Fig. 1B).

\section{Effect of high cholesterol diet on spontaneous uterine activity}

Spontaneous uterine activity, as determined by tension experiments, was not affected by a high cholesterol diet. Representative tracings of spontaneous activity are shown in Fig. 2A. The amplitude of the spontaneous contractions in control animals was $1.29 \pm 0.08 \mathrm{~g}(n=61$ strips) and that in $\mathrm{HC}$ diet-fed animals was $1.52 \pm 0.12 \mathrm{~g}$ ( $n=79$ strips) $(P=0.15)$. The frequency of the spontaneous contractions was $2.01 \pm 0.07$ per $\min (n=61$ strips $)$ in control and $1.89 \pm 0.1$ per min $(n=79$ strips $)$ in $\mathrm{HC}$ diet-fed mice $(P=0.39)$. The mean integral tension in control animals was $24.84 \pm 1.573 \mathrm{~g} \min (n=61$ strips), which was at par $(P=0.81)$ with the tension in $\mathrm{HC}$ diet-fed animals $(25.38 \pm 1.57 \mathrm{~g} \min , n=79$ strips). The contraction amplitude, frequency and MIT are depicted in Fig. 2B.

\section{Effect of high cholesterol diet on oxytocin-induced uterine contractility}

The representative tracings in Fig. 2C depict a concentration-dependent increase in contractile responses by oxytocin in the uterus of a standard diet-fed late pregnant mouse. After equilibration, the basal MIT of spontaneous rhythmic contraction was $23.89 \pm 2.79 \mathrm{~g} \min \quad(n=10)$. Oxytocin $\left(10^{-12}-10^{-6} \mathrm{M}\right)$ added at an increment of 0.5 log unit, caused a concentration-dependent increase in spontaneous rhythmic contractions (Fig. 2D). The $E_{\max }$ and $\mathrm{pD}_{2}$ of oxytocin-induced contractions were $556 \pm 28.17 \%$ and $8.18 \pm 0.17 \%$ respectively. The representative tracings in Fig. 2C illustrate the concentration-dependent increase in contractile responses by oxytocin in the late pregnant uterus of a HC diet-fed mouse. After equilibration, the basal MIT of spontaneous rhythmic contraction was $21.04 \pm 1.99 \mathrm{gmin}(n=10)$. The $E_{\max }$ and $\mathrm{pD}_{2}$ of oxytocin-induced contractions were $386.2 \pm 22.12 \%$ and $8.01 \pm 0.19 \%$ respectively in the uterus of a late pregnant mouse. High cholesterol diet attenuated oxytocin $\left(10^{-10}-10^{-6} \mathrm{M}\right)$-induced contractions $(P<0.001$ for $E_{\max }$ while $P=0.50$ for $\mathrm{pD}_{2}$ ) in late pregnant mouse uterus (Fig. 2D).

\section{Effect of high cholesterol diet on Pasteurella multocida toxin (PMT)-induced uterine contractility}

To demonstrate any effect of high cholesterol diet on GNAQ protein, we used an activator, Pasteurella

Table 2 Effect of high cholesterol diet on gestation length in late pregnant mice with or without exogenous administration of oxytocin.

\begin{tabular}{lcc}
\hline Gestation length (days) & Control & HC \\
\hline $\begin{array}{l}\text { Without oxytocin } \\
\quad \text { administration }\end{array}$ & $19.25 \pm 1.01(n=6)$ & $19.41 \pm 0.84(n=6)$ \\
$\begin{array}{l}\text { With oxytocin } \\
\text { administration }\end{array}$ & $18.59 \pm 0.07(n=5)^{\mathrm{a}}$ & $18.47 \pm 0.09(n=4)^{\mathrm{a}}$ \\
\hline
\end{tabular}

a $P<0.05$ as compared to without oxytocin in respective group of animals. Data were analyzed by two-way ANOVA followed by Bonferroni post hoc test. 

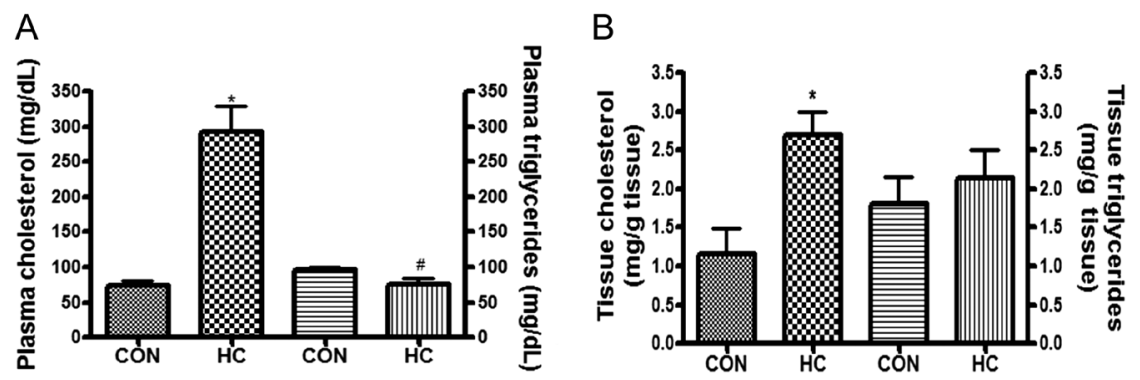

Figure 1 The effects of feeding either a control or $\mathrm{HC}$ diet for 6 weeks prior to and during pregnancy on the concentrations of total cholesterol and triglycerides in maternal plasma (A) and uterine tissue (B) on the 19th day of gestation in mice. Values are means with S.E.M. represented by vertical bars. Data were analyzed by unpaired $t$-test. * indicates $P<0.05$ as compared to cholesterol level in control mice and ${ }^{*}$ indicates $P<0.05$ as compared to triglyceride level in control mice.

A
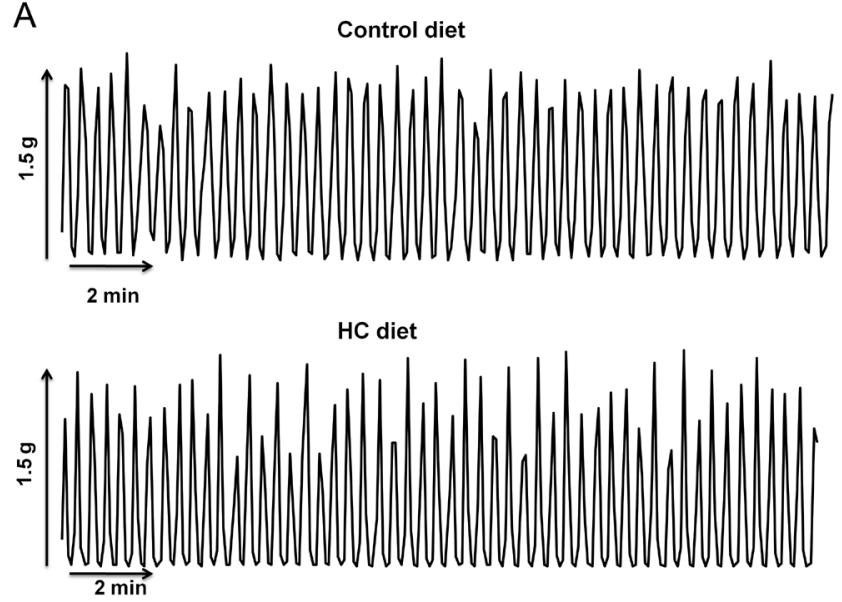

C
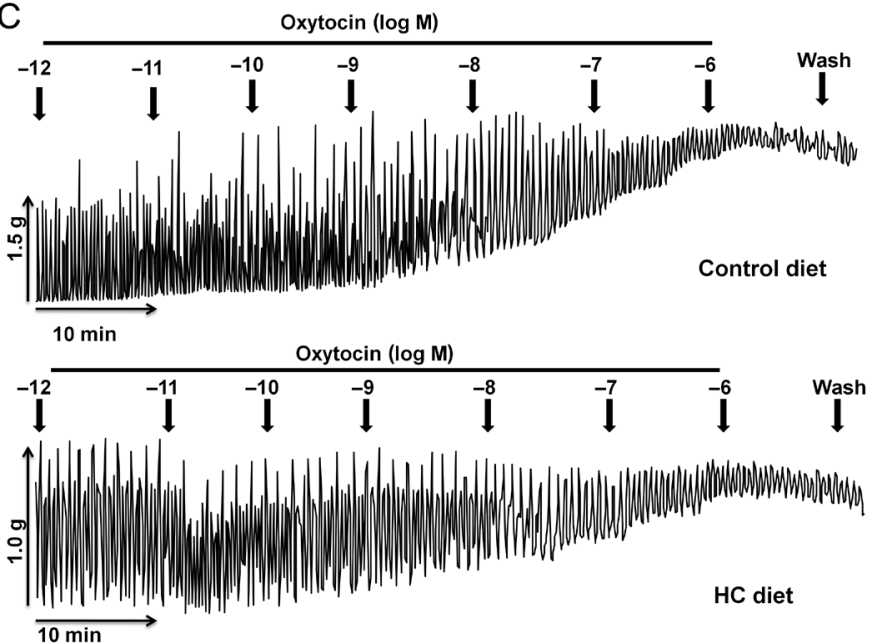

B
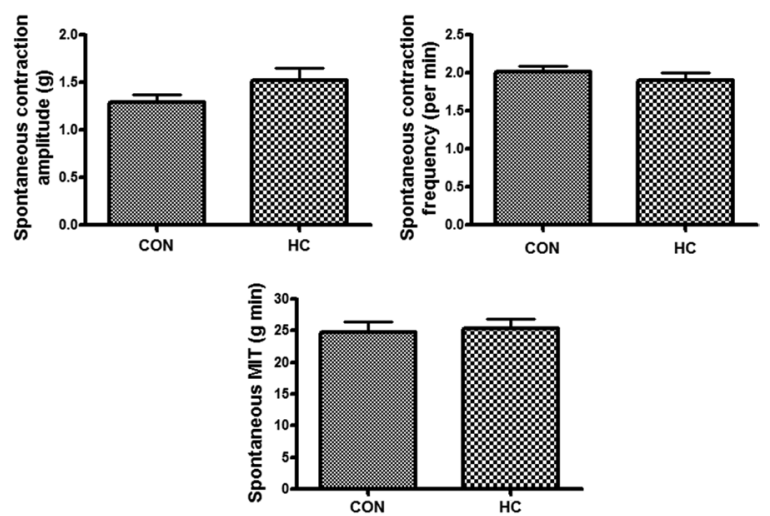

D

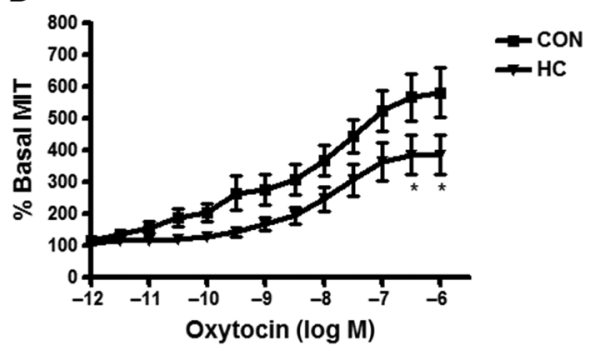

Figure 2 Representative tracings depict the effects of feeding either a control (CON) or HC diet (HC) for 6 weeks prior to and during pregnancy on the spontaneous uterine contractility (A) and the effect of oxytocin, added at a 0.5 log unit interval on spontaneous rhythmic uterine contraction (C). Spontaneous contractile amplitude, frequency and MIT in control and HC diet-fed mice were not significantly different from each other (B). Values are means with S.E.M. represented by vertical bars. Data were analyzed by unpaired $t$-test. (D) Line diagram of oxytocin concentration-response curve in pregnant uterus. Results are expressed as mean \pm S.E.M. Contractile response is expressed as a percentage of basal MIT of contractions. Data were analyzed by two-way ANOVA followed by Bonferroni post hoc test for multiple comparisons. ${ }^{*} P<0.05$. 
multocida toxin. PMT $\left(10^{-13}-10^{-9} \mathrm{M}\right)$, added cumulatively to uterine strips, produced a concentration-related contraction. HC diet significantly $(P<0.05)$ decreased the contractile response to PMT when compared with the contractions observed in tissues taken from standard diet-fed animals (Fig. 3A).

\section{Effect of high cholesterol diet on $\mathrm{CaCl}_{2}$-induced uterine contractility}

To demonstrate any effect of high cholesterol diet on voltage-sensitive calcium channels, concentration response to $\mathrm{CaCl}_{2}$ was obtained in $40 \mathrm{mM}$ potassiumdepolarized tissue. $\mathrm{CaCl}_{2} \quad\left(10^{-5}-10^{-2} \mathrm{M}\right)$ added cumulatively to $\mathrm{K}^{+}$-depolarized uterine strips produced a concentration-related contraction. The concentrationresponse curves in both the groups were overlapping (Fig. 3B).

\section{Effect of high cholesterol diet on m-3m3FBS-induced uterine relaxation}

To demonstrate any effect of high cholesterol diet on phospholipase C pathway, we used an activator, $m$-3m3FBS. $m-3 \mathrm{~m} 3 \mathrm{FBS}(0-50 \mathrm{mM})$ added cumulatively to uterine strips produced a concentration-related relaxation. The relaxation response was not significantly different between the two groups (Fig. 3C).

\section{Effect of high cholesterol diet on oxytocin-stimulated prostaglandin production in 19-day pregnant uterine tissue}

Oxytocin is known to mediate part of its uterine contractile effect through release of PGs (Ross et al. 2004). Therefore, we measured the PG release both in control and cholesterol-fed mice. Stimulation with oxytocin $1 \mu \mathrm{M}$ for $20 \mathrm{~min}$ significantly enhanced
$(P<0.01)$ the level of uterine prostaglandin in control mice $(831.2 \pm 194.6 \mathrm{pg} / \mathrm{mg}$ protein, $n=5$ vs basal, $400.7 \pm 67.30 \mathrm{pg} / \mathrm{mg}$ protein, $n=7$ ). Similarly, prostaglandin level was significantly increased $(P<0.001)$ in $\mathrm{HC}$ diet-fed mice $(841.7 \pm 124.7 \mathrm{pg} / \mathrm{mg}$ protein, $n=6$ vs basal, $102.4 \pm 3.26 \mathrm{pg} / \mathrm{mg}$ protein, $n=7)$. However, basal $(P>0.05)$, as well as oxytocinstimulated $(P>0.05)$ prostaglandin production, was not significantly different between the two groups (Fig. 4A).

\section{Effect of high cholesterol diet on plasma and tissue oxytocin levels}

Plasma and tissue levels of oxytocin (Fig. $4 \mathrm{~B}$ and C) were not affected $(P=0.53$ and 0.65$)$ in $\mathrm{HC}$ diet-fed animals $(5.52 \pm 2.11 \mathrm{IU} / \mathrm{mL}$ and $71.03 \pm 12.89 \mu \mathrm{IU} / \mathrm{mg}$ protein, $n=6$ each) as compared to control animals $(3.87 \pm 1.26 \mathrm{IU} / \mathrm{mL}$ and $58.00 \pm 24.95 \mu \mathrm{IU} / \mathrm{mg}$ protein, $n=6$ each).

\section{Effect of high cholesterol diet on oxytocin receptor mRNA expression on the 19th day of gestation}

As evident from real-time PCR study (Fig. 5A), high cholesterol diet did not influence $(P=0.88)$ the oxytocin receptor mRNA expression $(1 \pm 0.18, n=4$ vs control, $0.66 \pm 0.39, n=4)$.

\section{Effect of high cholesterol diet on oxytocin receptor, GNAQ, RHOA, GRK6 and CAV1 protein expressions on the 19th day of gestation}

Figure 5B depicts the representative blots for the oxytocin receptor, GNAQ, RhoA, GRK6 and CAV1 protein expressions in control and $\mathrm{HC}$ diet-fed groups of mice. Densitometric analysis of the Western blot data revealed a significant reduction $(P=0.025)$ in the OXTR protein expression in $\mathrm{HC}$ diet-fed mice compared to control animals (Fig. 5C). Control animals showed ACTB
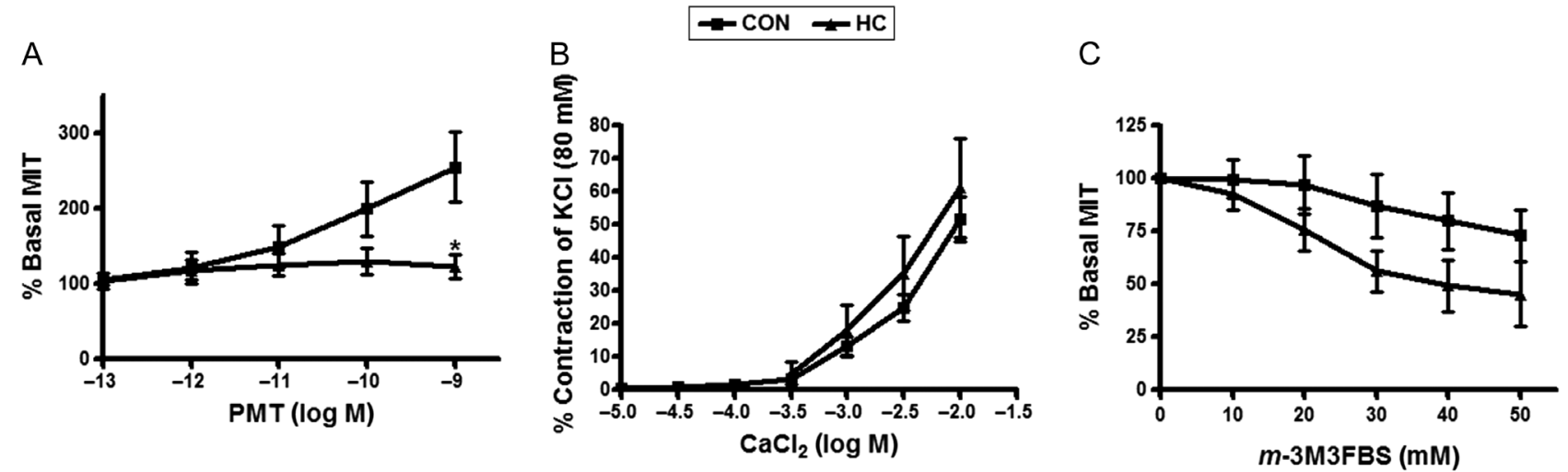

Figure 3 The effects of feeding either a control (CON) or $\mathrm{HC}$ diet $(\mathrm{HC})$ for 6 weeks prior to and during pregnancy on exogenously added (A) Pasteurella multocida toxin (PMT), (B) $\mathrm{CaCl}_{2}$ and (C) $m$-3M3FBS response in longitudinal uterine strips on the 19th day of gestation in mice. Values are means with S.E.M. represented by vertical bars. Data were analyzed by two-way ANOVA followed by Bonferroni post hoc test. $* P<0.05$ compared to basal MIT in control mice. 

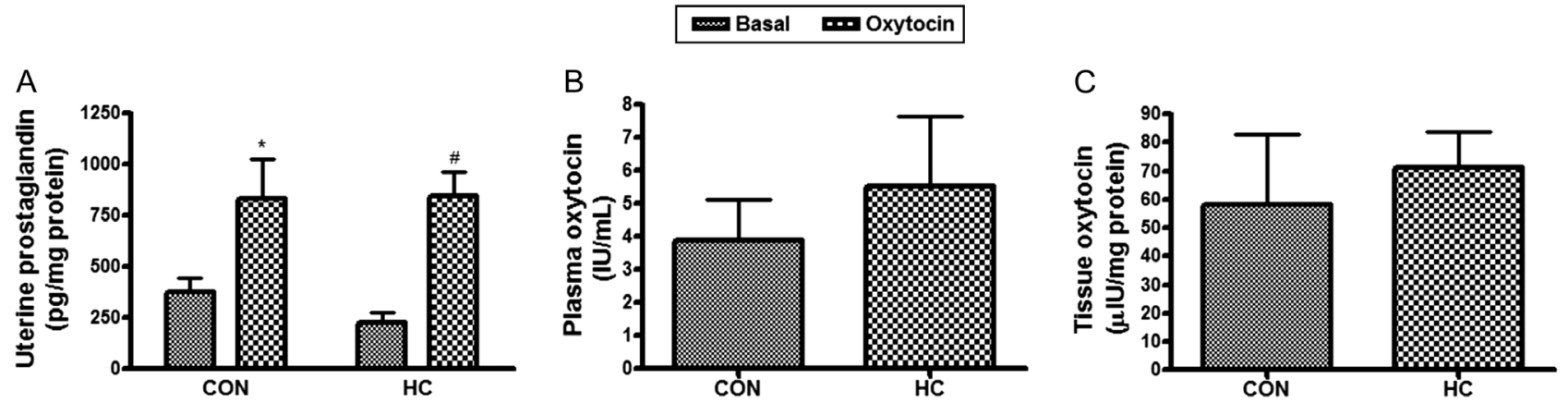

Figure 4 The effects of feeding either a control $(\mathrm{CON})$ or $\mathrm{HC}$ diet $(\mathrm{HC})$ for 6 weeks prior to and during pregnancy on (A) oxytocin-stimulated prostaglandin release, (B) concentrations of oxytocin in maternal plasma and (C) uterine tissue on the 19th day of gestation in mice. Values are means with S.E.M. represented by vertical bars. Data were analyzed by Two-way ANOVA followed by Bonferroni post hoc test (A) and unpaired $t$-test (B \& C). *, \# indicate $P<0.01$ compared to the basal levels in CON and HC groups, respectively.

normalized value of $1.15 \pm 0.11(n=6)$ as compared to $0.75 \pm 0.101$ for HC animals $(n=6)$. Similar was the protein expression for GNAQ $(0.24 \pm 0.01, n=6$ vs control, 0.66 $\pm 0.106, n=6 ; P=0.002$, Fig. 5D), which showed significant decrease in reference protein normalized values. The activation of the RhoA protein by the OXTR is another pathway that results in increased MLC phosphorylation and myometrial contraction. RhoA protein expression level was also decreased $(0.07 \pm 0.02$, $n=3$ vs control, $0.28 \pm 0.02, n=3 ; P=0.004$, Fig. $5 \mathrm{E}$ ) in hypercholesterolemic mice uteri. Along with proteins of downstream oxytocin signaling, we also measured the protein mass of GRK6 and CAV1. GRK6 is an enzyme responsible for phosphorylation and desensitization of oxytocin receptors (Grotegut et al. 2016). Whereas CAV1 is the protein associated with caveolae. Caveolae are involved in mediating homologous and heterologous desensitization of receptors in smooth muscles (Murthy \& Makhlouf 2000, Mahavadi et al. 2013). HC diet significantly increased GRK6 (1.01 $\pm 0.16, n=4$ vs control, $0.45 \pm 0.06, n=4 ; P=0.02$, Fig. 5F) and CAV1 $(1.55 \pm 0.28, n=5$ vs control, $0.74 \pm 0.19, n=5 ; P=0.04$, Fig. 5G) protein expressions.

\section{Discussion}

The prevalence of hypercholesterolemia (total cholesterol $\geq 6.5 \mathrm{mmol} / \mathrm{L}$ ) ranged across populations from $3 \%$ to $53 \%$ in men, and from $4 \%$ to $40 \%$ in women (Tolonen et al. 2005). Hypercholesterolemia in pregnant women affects pregnancy outcome, though controversial opinions exist. A prospective observational cohort study in Africa reports the association of high maternal serum cholesterol with pre-term delivery and low birth weight in term infants (Maymunah et al. 2014). But a retrospective study in Norway denies such association (Toleikyte et al. 2011).

In the current study, we used an atherogenic diet (Shi et al. 2002) to produce hypercholesterolemia in mice. Feeding of this diet for 6 weeks before mating and continuing up to the 19th day of gestation raised the plasma cholesterol three times compared to that in the control mice. The level of cholesterol $(272.4 \pm 22.04 \mathrm{mg} /$ dL) was comparable to hypercholesterolemic women ( $\geq 250.96 \mathrm{mg} / \mathrm{dL}$, Tolonen et al. 2005). But the diet did not change the body weight significantly in the mice throughout the study period. So the diet was able to create hypercholesterolemia without causing obesity. The diet also successfully elevated the local cholesterol level in uterine tissue parallel to that in plasma. On the other hand, plasma triglyceride level was significantly reduced although the uterine triglycerides level did not alter. Thus the mice model was relevant to study the effects of increased cholesterol in uterine tissue without considering the effects of triglycerides.

The main observations of the present investigation are: (1) hypercholesterolemia impaired uterine contractions elicited by GPCR agonist oxytocin in vitro; (2) it also dampened contractions induced by GNAQ protein activator $P$. multocida toxin; (3) however, it had no effect either on spontaneous contractions or $\mathrm{CaCl}_{2}$ induced contractions in $\mathrm{K}^{+}$-depolarized uterine strips; (4) consistent with functional studies, we observed that hypercholestetrolemia decreased the expression of oxytocin receptor, GNAQ protein, and RHOA protein expressions, and increased the GRK6 protein expression; (5) additionally, CAV1 protein expression was augmented; and (6) though mRNA expression of oxytocin receptor was not affected.

We observed in a set of preliminary experiments that both control and hypercholesterolemic animals gave birth to pups on day 19 of pregnancy. Accordingly, we used the uterine tissue strips of 19-day pregnant mice before parturition for all our experiments. Further, hypercholesterolemia did not influence the parturition time upon exogenous oxytocin administration.

Our observations in isolated uterine tissue activity revealed that the spontaneous uterine contractility was not influenced in hypercholesterolemic mice. Spontaneous contractility of rodent uterus primarily 

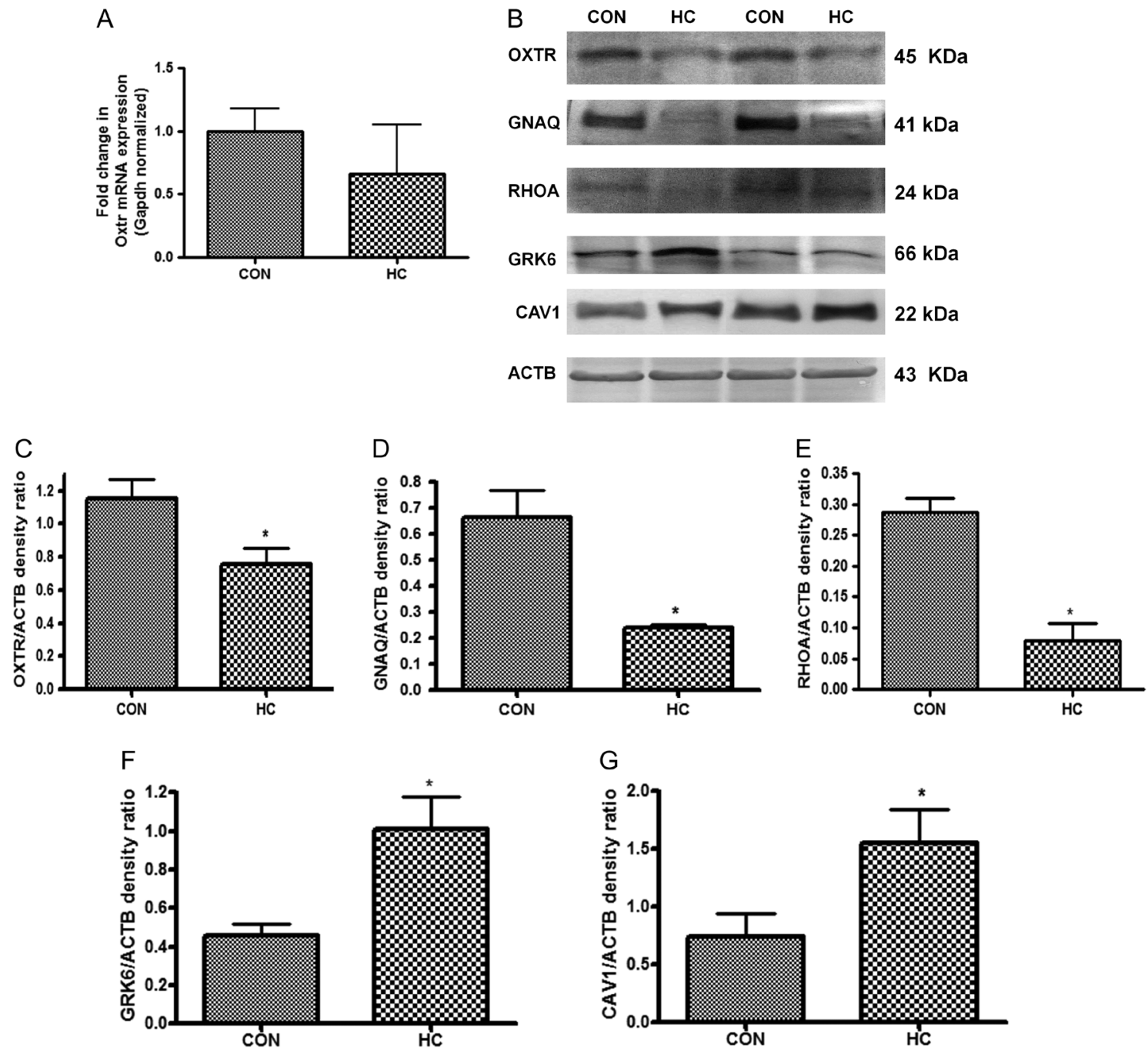

Figure 5 The effects of feeding either a control (CON) or $\mathrm{HC}$ diet $(\mathrm{HC})$ for 6 weeks prior to and during pregnancy on (A) mRNA expression of oxytocin receptor (Oxtr) and (B) protein expression of OXTR, GNAQ, RHOA, GRK6, CAV1 and $\beta$-actin (ACTB) proteins. Densitometric analysis of the blots confirmed the significant changes of these proteins (C, D, E, F and G) in uterine total membrane protein on the 19th day of gestation in mice. Values are means with S.E.M. represented by vertical bars. Mann-Whitney test was applied to compare the $\Delta C_{\mathrm{T}}$ values from the control and $\mathrm{HC}$ diet-fed groups. Unpaired $t$-test was used to compare the normalized band density between the two groups. Difference between control and $\mathrm{HC}$ mice was considered significant at the level of $P<0.05\left(^{*}\right)$.

depends on extracellular $\mathrm{Ca}^{2+}$ (Bolton 1979). In accordance, we found an overlapping $\mathrm{CaCl}_{2}$ response in depolarized uterine tissues of both the groups of animals, which indicates that hypercholesterolemia had little effect on voltage-dependent $\mathrm{Ca}^{2+}$ channels, responsible for the extracellular $\mathrm{Ca}^{2+}$ influx. In the obese rat model, Muir and coworkers (Muir et al. 2016) also observed no alteration in mean integral tension, amplitude and frequency of spontaneous contractility in non-laboring rats. However, older reports depicting the effect of ex vivo cholesterol manipulation in uterine tissues indicated that increased cholesterol decreases uterine activity and cholesterol depletion can enhance spontaneous uterine contractility (Smith et al. 2005, Shmygol et al. 2007).
The purpose of measuring oxytocin in plasma as well as uterine tissue was two-fold: one was to examine the effect of high-fat diet on the endogenous production of this hormone, primarily responsible for induction of labor; the second purpose was to study if excess oxytocin production in cholesterol-fed animals was in any way responsible for the desensitization of OXTR receptors in these animals. The results suggest that the elevated cholesterol level did not influence the endogenous release of the hormone primarily responsible for the induction of labor. However, exogenous application of oxytocin to these tissues displayed a significant reduction of the maximal response in hypercholesterolemic animals albeit the $\log \mathrm{EC}_{50}$ values were not different. This observation is comparable to the ex vivo studies 
with the application of exogenous cholesterol in uterine tissues (Smith et al. 2005). But in the obese rat model, the authors reported that HFHC diet blunted the oxytocin responses during labor although there was no alteration in oxytocin-induced uterine contractility in non-laboring rats (Muir et al. 2016).

In accordance with pharmacological observations, we foundanotabledeclineintheoxytocin receptorexpression in the membrane protein of hypercholesterolemic animals by Western blot studies. The downregulation of OXTR proteins may be related to alteration in their mRNA expression, phosphorylation and internalization of the active proteins or due to post-translational anchoring. We observed no change in mRNA expression of Oxtr, which suggested that the Oxytocin receptor is regulated after its translation to protein and not at the genomic level. Interestingly, GRK6 protein expression was significantly increased in hypercholesterolemic mice. Oxytocin receptor responsiveness has been shown to be regulated by GRK6 in human myometrial smooth muscle (Willets et al. 2009). Mice lacking GRK6 have exhibited enhanced uterine contractility due to deficient OXTR desensitization (Grotegut et al. 2016). Increased GRK6 expression in hypercholesterolemic mouse uterus indicates that this may be one of the reasons responsible for OXTR downregulation. In accordance, a recent study demonstrated that cholesterol depletion by $\beta$-cyclodextrin totally suppressed agonist-induced internalization of oxytocin receptors (Brejchova et al. 2016). So, without augmentation of OXTR desensitization in our study is intriguing as endogenous oxytocin release was not augmented. This may suggest a direct interaction between cholesterol and OXTR, as binding sites for both agonist and cholesterol are localized in the same receptor segment (Wiegand \& Gimpl 2012).

As mentioned previously, OXTR like other GPCRs along with its immediate signaling molecules resides in specific membrane compartments called lipid rafts and caveolae. These compartments act as centers for signaling cascades. Interesting studies in the past demonstrated the delicate regulation of signaling of OXTR (Rimoldi et al. 2003, Reversi et al. 2006) due to inclusion and exclusion of the signaling components in these microdomains. In the current study, we found a significant increase in CAV1, a caveolae marker protein in the cell membrane of hypercholesterolemic animals. In prostate tissue, oxytocin provokes a proliferative response when the oxytocin receptor is localized mainly in CAV1-enriched domains and an anti-proliferative effect when the same receptor is not localized in caveolae (Herbert et al. 2007). Though such information is not available for contractile OXTRs of the uterus, it is possible that CAV1 enriched fractions in hypercholesterolemic mice modulate the OXTR localization to cause reduced signaling efficiency and reduced response.

As oxytocin signaling is mediated mostly by $\mathrm{Gq} / 11$ protein, we used a GNAQ protein activator PMT for assessing the uterine response independent of any receptor agonist. PMT causes constitutive activation of $G$ proteins by deamidase activity. In isolated uterine tissues, PMT produced a concentration-dependent increase of contractile response in control mice, which was attenuated in hypercholesterolemic mice. This finding was also supported by the Western blot data, where a considerable reduction in GNAQ protein was found in hypercholesterolemic mice. This indicated the reduction in signaling efficacy of the OXTR in hypercholesterolemic mouse uterus. Cholesterol depletion was shown not to affect the binding characteristics of TRH receptor, a GPCR like OXTR, but to markedly alter the efficacy of signal transduction mediated by Gq/11 (Ostasov et al. 2007).

In addition, PMT is an activator of Rho GTPases independent of Gq proteins (Blöcker et al. 2006). RhoA is a small GTPase that can inhibit myosin light chain phosphatase and/or activate Rho kinase (ROCK) to promote the contractility of smooth muscles (Puetz et al. 2009). Oxytocin through the OXTR can activate the RhoA-ROCK cascade that results in increased MLC phosphorylation and myometrial contraction (Arthur et al. 2007). In the current study, we noticed a significant downregulation of RhoA protein in hypercholesterolemic mice suggesting a possible effect on this pathway, which leads to suppressed oxytocin response.

Further, we evaluated the effect of direct activation of phospholipase $\mathrm{C}$ independent of oxytocin stimulation. Surprisingly, selective PL-C activation by $m-3 \mathrm{~m} 3 \mathrm{FBS}$, which was supposed to raise intracellular $\mathrm{Ca}^{2+}$ content, produced concentration-dependent relaxation of the uterine tissue. This was proved to be the result of activation of abundant $\mathrm{Ca}^{2+}$-sensitive $\mathrm{K}^{+}$channels by the reversal of such relaxation by selective BKca channel blocker, iberiotoxin (data not shown). Hypercholesterolemia did not affect direct PL-C-activated response in the uterus. This suggests the effect of high cholesterol at the receptor and its nearby component G-protein and not on distal signaling pathways like phospholipase C. Another mechanism of oxytocin producing uterine contractility is the stimulation of cellular synthesis of prostaglandins (Soloff et al. 2000). We observed that hypercholesterolemic uteri were equally efficient as control uteri in releasing prostaglandins consequent to oxytocin stimulation.

Uterine smooth muscle is unique to show the opposite effect of high cholesterol content as compared to other smooth muscles. Increased cholesterol in pregnancy may be linked to maintenance of quiescence until parturition. One of the mechanisms for this phenomenon may be the reduced number of active uterine OXTRs due to desensitization or selective compartmentalization. Abnormal hypercholesterolemia may foster this by inhibiting the signaling of these receptors through GNAQ and RHOA proteins. 
In conclusion, hypercholesterolemia is a condition although crucial in cardiovascular disorders has particular significance in physiology and pathology of reproductive disorders. Even if the particular model used in the study did not affect the overall contractility of the uterus, it elicited a notable effect on oxytocin response. Oxytocin is a major contractile agent and is used clinically for augmentation of labor during dysfunctional labor. Though further study is required in a clinical setting, the clinician must take note of reduced efficacy of oxytocin in hypercholesterolemic patients. Moreover, studies may be directed to reveal the regulation of these receptors in caveolar and noncaveolar plasma membrane as well as to disclose any direct interaction of the receptor with cholesterol to cause its desensitization in in vivo models.

\section{Declaration of interest}

The authors declare that there is no conflict of interest that could be perceived as prejudicing the impartiality of the research reported.

\section{Funding}

This work was funded by the Department of Biotechnology (DBT), Ministry of Science and Technology, Government of India, New Delhi.

\section{Acknowledgements}

The Senior Research Fellowship (SRF) awarded to the first author by the Indian Council of Agricultural Research (ICAR), New Delhi, is gratefully acknowledged. The authors are thankful to the Director, Indian Veterinary Research Institute, for providing necessary facilities.

\section{References}

Arthur P, Taggart MJ \& Mitchell BF 2007 Oxytocin and parturition: a role for increased myometrial calcium and calcium sensitization? Frontiers in Bioscience 12 619-633. (doi:10.2741/2087)

Arthur P, Taggart MJ, Zielnik B, Wong S \& Mitchell BF 2008 Relationship between gene expression and function of uterotonic systems in the rat during gestation, uterine activation and both term and preterm labour. Journal of Physiology 586 6063-6076. (doi:10.1113/ jphysiol.2008.164004)

Blöcker D, Berod L, Fluhr JW, Orth J, Idzko M, Aktories K \& Norgauer J 2006 Pasteurella multocida toxin (PMT) activates RhoGTPases, induces actin polymerization and inhibits migration of human dendritic cells, but does not influence macropinocytosis. International Immunology 18 459-464. (doi:10.1093/intimm/dxh386)

Bolton TB 1979 Mechanisms of action of transmitters and other substances on smooth muscle. Physiological Reviews 59 606-718.

Brainard AM, Miller AJ, Martens JR \& England SK 2005 Maxi-K channels localize to caveolae in human myometrium: a role for an actin-channelcaveolin complex in the regulation of Myometrial smooth muscle $\mathrm{K}^{+}$ current. American Journal of Physiology: Cell Physiology 289 C49-C57. (doi:10.1152/ajpcell.00399.2004)

Brejchova J, Vosahlikova M, Roubalova L, Parenti M, Mauri M, Chernyavskiy O \& Svoboda P 2016 Plasma membrane cholesterol level and agonist-induced internalization of $\delta$-opioid receptors; colocalization study with intracellular membrane markers of Rab family. Journal of Bioenergetics and Biomembranes 13 1-22. (doi:10.1007/s10863-0169667-7)

Buxton IL \& Vittori JC 2005 Cholesterol depletion enhances both spontaneous and agonist-evoked uterine smooth muscle contractions in a reversible manner. Proceedings of the Western Pharmacology Society 48126.

Devost D \& Zingg HH 2003 Identification of dimeric and oligomeric complexes of the human oxytocin receptor by co-immunoprecipitation and bioluminescence resonance energy transfer. Journal of Molecular Endocrinology 31 461-471. (doi:10.1677/jme.0.0310461)

Draeger A, Wray S \& Babiychuk EB 2005 Domain architecture of the smooth-muscle plasma membrane: regulation by annexins. Biochemical Journal 387 309-314. (doi:10.1042/BJ20041363)

Elmes MJ, Tan DS, Cheng Z, Wathes DC \& McMullen S 2011 The effects of a high-fat, high-cholesterol diet on markers of uterine contractility during parturition in the rat. Reproduction 141 283-290. (doi:10.1530/ REP-10-0378)

Gater DL, Saurel O, Iordanov I, Liu W, Cherezov V \& Milon A 2014 Two classes of cholesterol binding sites for the $\beta_{2} A R$ revealed by thermostability and NMR. Biophysical Journal 107 2305-2312. (doi:10.1016/j.bpj.2014.10.011)

Gimpl G \& Fahrenholz F 2000 Human oxytocin receptors in cholesterolrich vs cholesterol-poor microdomains of the plasma membrane. European Journal of Biochemistry 267 2483-2497. (doi:10.1046/j.14321327.2000.01280.x)

Gimpl G \& Fahrenholz F 2002 Cholesterol as stabilizer of the oxytocin receptor. Biochimica et Biophysica Acta 1564 384-392. (doi:10.1016/ S0005-2736(02)00475-3)

Gimpl G, Burger K \& Fahrenholz F 1997 Cholesterol as modulator of receptor function. Biochemistry 36 10959-10974. (doi:10.1021/ bi963138w)

Gostynski M, Gutzwiller F, Kuulasmaa K, Döring A, Ferrario M, Grafnetter D, Pajak A \& WHO MONICA Project 2004 Analysis of the relationship between total cholesterol, age, body mass index among males and females in the WHO MONICA Project. International Journal of Obesity and Related Metabolic Disorders 28 1082-1090. (doi:10.1038/ sj.ijo.0802714)

Grotegut CA, Mao L, Pierce SL, Swamy GK, Heine RP \& Murtha AP 2016 Enhanced uterine contractility and stillbirth in mice lacking $G$ proteincoupled receptor kinase 6 (GRK6): implications for oxytocin receptor desensitization. Molecular Endocrinology 30 455-468. (doi:10.1210/ me.2015-1147)

Hara A \& Radin NS 1978 Lipid extraction of tissues with a low-toxicity solvent. Analytical Biochemistry 90 420-426. (doi:10.1016/00032697(78)90046-5)

Herbert Z, Bötticher G, Aschoff A, Sendemir E, Zermann DH, Arnold R, Mall G \& Jirikowski GF 2007 Changing Caveolin-1 and oxytocin receptor distribution in the ageing human prostate. Anatomia, Histologia, Embryologia 36 361-365. (doi:10.1111/j.1439-0264.2007.00775.x)

Livak KJ \& Schmittgen TD 2001 Analysis of relative gene expression data using real time quantitative PCR and the 2-DDCT method. Methods 25 402-408. (doi:10.1006/meth.2001.1262)

Maymunah AO, Kehinde O, Abidoye G \& Oluwatosin A 2014 Hypercholesterolaemia in pregnancy as a predictor of adverse pregnancy outcome. African Health Sciences 14 967-973. (doi:10.4314/ahs. v14i4.28)

Ross RG, Sathishkumar K, Naik AK, Bawankule DU, Sarkar SN, Mishra SK \& Prakash VR 2004 Mechanisms of lipopolysaccharide induced changes in effects of contractile agonists on pregnant ratmyometrium. American Journal of Obstetrics and Gynecology 190 532-540. (doi:10.1016/ S0002-9378(03)00949-9)

Mahavadi S, Bhattacharya S, Kim J, Fayed S, Al-Shboul O, Grider JR \& Murthy KS 2013 Caveolae-dependent internalization and homologous desensitization of VIP/PACAP receptor, VPAC2, in gastrointestinal smooth muscle. Peptides 43 137-145 (doi:10.1016/j.peptides.2013.03.008)

Mouse Genome Sequencing Consortium, Waterston RH, Lindblad-Toh K, Birney E, Rogers J, Abril JF, Agarwal P, Agarwala R, Ainscough R, Alexandersson $\mathbf{M}$ et al. 2002 Initial sequencing and comparative analysis of the mouse genome. Nature 420 520-562. (doi:10.1038/nature01262)

Mouzat K, Prod'homme M, Volle DH, Sion B, Déchelotte P, Gauthier K, Vanacker JM \& Lobaccaro JM 2007 Oxysterol nuclear receptor LXRbeta 
regulates cholesterol homeostasis and contractile function in mouse uterus. Journal of Biological Chemistry 282 4693-46701. (doi:10.1074/ jbc.M606718200)

Muir R, Ballan J, Clifford B, McMullen S, Khan R, Shmygol A, Quenby S \& Elmes M 2016 Modelling maternal obesity: the effects of a chronic highfat, high-cholesterol diet on uterine expression of contractile-associated proteins and ex vivo contractile activity during labour in the rat. Clinical Science 130 183-192. (doi:10.1042/CS20150539)

Murthy KS \& Makhlouf GM 2000 Heterologous desensitization mediated by G protein-specific binding to caveolin. Journal of Biological Chemistry 275 30211-30219. (doi:10.1074/jbc.M002194200)

Muth S, Fries A \& Gimpl G 2011 Cholesterol-induced conformational changes in the oxytocin receptor. Biochemical Journal 437 541-553. (doi:10.1042/bj20101795)

Noble K, Zhang J \& Wray S 2006 Lipid rafts, the sarcoplasmic reticulum and uterine calcium signalling: an integrated approach. Journal of Physiology 570 29-35. (doi:10.1113/jphysiol.2005.098475)

Ostasov P, Bourova L, Hejnova L, Novotny J \& Svoboda P 2007 Disruption of the plasma membrane integrity by cholesterol depletion impairs effectiveness of TRH receptor-mediated signal transduction via $G \mathrm{q} /$ G11 $\alpha$ proteins. Journal of Receptors and Signal Transduction 27 335-352. (doi:10.1080/10799890701684142)

Parida S, Singh TU, Ravi Prakash V \& Mishra SK 2013 Molecular and functional characteristics of $\beta_{3}$-adrenoceptors in late pregnant mouse uterus: a comparison with $\beta_{2}$-adrenoceptors. European Journal of Pharmacology 700 74-79. (doi:10.1016/j.ejphar.2012.11.048)

Potter J \& Nestel PJ 1978 Cholesterol balance during pregnancy. Clinica Chimica Acta 87 57-61. (doi:10.1016/0009-8981(78)90057-8)

Puetz S, Lubomirov LT \& Pfitzer G 2009 Regulation of smooth muscle contraction by small GTPases. Physiology 24 342-356. (doi:10.1152/ physiol.00023.2009)

Reversi A, Rimoldi V, Brambillasca S \& Chini B 2006 Effects of cholesterol manipulation on the signaling of the human oxytocin receptor. American Journal of Physiology: Regulatory Integrative and Comparative Physiology 291 R861-R869.

Rimoldi V, Reversi A, Taverna E, Rosa P, Francolini M, Cassoni P, Parenti M \& Chini B 2003 Oxytocin receptor elicits different EGFR/MAPK activation patterns depending on its localization in caveolin-1 enriched domains. Oncogene 22 6054-6060. (doi:10.1038/sj.onc.1206612)

Sanborn BM, Ku CY, Shlykov S \& Babich L 2005 Molecular signaling through G-protein-coupled receptors and the control of intracellular calcium in myometrium. Journal of the Society for Gynecologic Investigation 12 479-487. (doi:10.1016/j.jsgi.2005.07.002)

Shi W, Wang X, Shih DM, Laubach VE, Navab M \& Lusis AJ 2002 Paradoxical reduction of fatty streak formation in mice lacking endothelial nitric oxide synthase. Circulation 105 2078-2082. (doi:10.1161/01. CIR.0000015853.59427.32)

Shmygol A, Noble K \& Wray S 2007 Depletion of membrane cholesterol eliminates the $\mathrm{Ca} 2+$-activated component of outward potassium current and decreases membrane capacitance in rat uterine myocytes. Journal of Physiology 581 445-456. (doi:10.1113/jphysiol.2007.129452)
Singh V, Ram M, Kandasamy K, Thangamalai R, Choudhary S, Dash JR, Kumar D, Parida S, Singh TU \& Mishra SK 2015 Molecular and functional characterization of TRPV4 channels in pregnant and nonpregnant mouse uterus. Life Science 122 51-58. (doi:10.1016/j.Ifs.2014.12.010)

Smith RD, Babiychuk EB, Noble K, Draeger A \& Wray S 2005 Increased cholesterol decreases uterine activity: functional effects of cholesterol alteration in pregnant rat myometrium. American Journal of Physiology: Cell Physiology 288 982-988. (doi:10.1152/ajpcell.00120.2004)

Soloff MS, Jeng YJ, Copland JA, Strakova Z \& Hoare S 2000 Signal pathways mediating oxytocin stimulation of prostaglandin synthesis in select target cells. Experimental Physiology 85 51s-58s. (doi:10.1111/ j.1469-445X.2000.tb00007.x)

Soubias O \& Gawrisch K 2013 Rhodopsin-lipid interactions studied by NMR. Methods in Enzymology 522 209-227. (doi:10.1016/B978-0-12407865-9.00012-1)

Toleikyte I, RetterstøI K, Leren TP \& Iversen PO 2011 Pregnancy outcomes in familial hypercholesterolemia a registry-based study. Circulation 124 1606-1614. (doi:10.1161/CIRCULATIONAHA.110.990929)

Tolonen H, Keil U, Ferrario M \& Evans A 2005 Prevalence, awareness and treatment of hypercholesterolaemia in 32 populations: results from the WHO MONICA Project. International Journal of Epidemiology 34 181-192. (doi:10.1093/ije/dyi056)

Villar VA, Cuevas S, Zheng X \& Jose PA 2016 Localization and signaling of GPCRs in lipid rafts. Methods in Cell Biology 132 3-23. (doi:10.1016/ bs.mcb.2015.11.008)

Weiss JL, Malone FD, Emig D, Ball RH, Nyberg DA, Comstock CH, Saade G, Eddleman K, Carter SM, Craigo SD et al. 2004 Obesity, obstetric complications and cesarean delivery rate - a population-based screening study. American Journal of Obstetrics and Gynecology 190 1091-1097. (doi:10.1016/j.ajog.2003.09.058)

Wiegand V \& Gimpl G 2012 Specification of the cholesterol interaction with the oxytocin receptor using a chimeric receptor approach. European Journal of Pharmacology 676 12-19. (doi:10.1016/j.ejphar.2011.11.041)

Willets JM, Brighton PJ, Mistry R, Morris GE, Konje JC \& Challiss RJ 2009 Regulation of oxytocin receptor responsiveness by $\mathrm{G}$ protein-coupled receptor kinase 6 in human myometrial smooth muscle. Molecular Endocrinology 23 1272-1280. (doi:10.1210/me.2009-0047)

Zhang J, Kendrick A, Quenby S \& Wray S 2007 Contractility and calcium signaling of human myometrium are profoundly affected by cholesterol manipulation: implications for labor? Reproductive Sciences 14 456-466. (doi:10.1177/1933719107306229)

Received 12 August 2016

First decision 14 September 2016

Revised manuscript received 10 February 2017

Accepted 27 February 2017 